\title{
Columbiners. Działalność Serial Killer Fandom w środowisku True Crime Community
}

\section{Columbiners: The activity of Serial Killer Fandom within True Crime Community}

DOI: $10.12775 /$ LL.2.2021.007 | CC BY-ND 3.0 PL

ABSTRACT: Eric Harris and Dylan Klebold are responsible for one of the most tragic mass school shootings in the US, know as The Columbine High School Massacre. This event brought about nation-wide moral panic concerning the depiction of violence in digital games, music and film. Interestingly, the teen murders have accumulated a fan base whose members are active online and refer to themselves as Columbiners. This fandom is a peculiar subgroup of True Crime Community, a larger community interested in criminology and the psychology of felons. The worship-like admiration of both serial and mass killers - particularly by women - is not a new phenomenon; there have been attempts to explain it away in the context of paraphilia and evolution. However, the fans of Columbine High School shooters elude such interpretations. This article analyses the case of Columbine fandom to demonstrate that the fascination with the murders need not involve sexualization, but can develop through empathizing and identifying with the criminals resulting from the radical recontextualization of their image in the digital pace.

KEYWORDS: fandom, Columbine, True Crime Community, serial killers

20 kwietnia 1999 r., w 110. rocznicę urodzin Adolfa Hitlera, 18-letni wówczas uczniowie ostatniej klasy szkoły średniej, Eric Harris i Dylan Klebold, weszli na teren Columbine High School z bronią palną. Zabili 12 uczniów, jednego na- 
uczyciela i zranili 24 rówieśników. Po niecałej godzinie od rozpoczęcia strzelaniny, zanim do budynku wkroczyła policja, popełnili podwójne samobójstwo w bibliotece, w której znajdowały się ciała dziesięciorga ofiar. Społecznymi i kulturowymi konsekwencjami tego wydarzenia, nazwanego masakrą w Columbine High School, były panika moralna ${ }^{1}$ w związku z przemocą w grach komputerowych, marginalizacją społeczną i znęcaniem się w szkole, dyskusja nad zaostrzeniem prawa do posiadania broni w Stanach Zjednoczonych oraz tzw. „efekt Columbine”, czyli niechlubne dziedzictwo w formie naśladowania masowego morderstwa Harrisa i Klebolda w atakach na inne placówki edukacyjne i miejsca publiczne. Na tym jednak wpływ masakry w Columbine się nie kończy. Chociaż minęło ponad 20 lat od tego tragicznego zdarzenia, pamięć o nastoletnich mordercach jest wciąż pielęgnowana w pewnych społecznościach internetowych, gdzie oni sami i ich działania stają się obiektem fanowskiego afektu. W dobie kultury cyfrowej „spuścizna” Harrisa i Klebolda zrzesza twórczych fanów, którzy gloryfikują i romantyzują ich zbrodnie, przedstawiając nastoletnich zabójców jako postacie tragiczne. Najliczniejsze grupy fanów tego typu można zaobserwować na platformie Tumblr (Smith, 2018-2019, s. 140).

Niniejszy artykuł ma na celu przedstawienie fandomu Columbiners, a w szczególności rekontekstualizacji wydarzeń związanych z masakrą w Columbine High School oraz reinterpretacji zbrodni i poprzedzających ją działań. Struktury reinterpretacji staną się także przyczynkiem dla wyjaśnienia fenomenu popularności nastoletnich zabójców w kontekście dobrze udokumentowanej na gruncie psychologii fascynacji kobiet seryjnymi mordercami (Duclos, 1998; Schmidt, 2005; Bonn, 2014). Już proces Teda Bundy’ego w 1979 r. ściągnął na salę sądową całe rzesze młodych kobiet, które w równej mierze wyrażały strach i fascynację postacią seryjnego mordercy (Smith, 2018-2019, s. 141). Rewolucja medialna i powszechna cyfryzacja umożliwiły bezpiecznie przeżywanie tego afektywnego splotu wstrętu i fascynacji w anonimowej przestrzeni internetu, w zaciszu własnego domu, a także dzielenie się tymi odczuciami $\mathrm{z}$ podobnie nastwionymi jednostkami. W efekcie powstały liczne internetowe fandomy skupione wokół zjawiska true crime, czyli paradokumentalnych form kryminalistycznych narracji realizowanych w różnych mediach (filmy, książki, seriale, podcasty), a także wokół samych postaci morderców (Smith, 2018-2019, s. 144). Jednocześnie w kulturze popularnej zachodzi proces określany jako „celebryfikacja” seryjnych morderców (Duwe, 20oo; Driessens, 2013; Binik, 2020). Fikcyjni mordercy opanowują masową wyobraźnię od czasu publikacji Milczenia owiec Thomasa Harrisa w 1988 r. (nagłośnionej przez oskarową ekranizację z 1992 r.), opisy krwawych zbrodni trafiają na nagłówki gazet jako gwarancja

1 Panika moralna to pojęcie wprowadzone przez Stanleya Cohena w 1972 r. do opisu reakcji społeczeństwa na powstanie i popularyzację subkultur młodzieżowych. Cohen określił panikę moralną jako reakcję na łamanie obowiązujących zasad społecznych i powiązał z nią takie mechanizmy jak marginalizacja, demonizacja, przesadzona reakcja i kluczowa rola mediów w procesie jej podtrzymywania i rozpowszechniania. 
wzrostu sprzedaży (obecnie „klikalności”), pozycje z zakresu kryminalistyki sytuują się na szczytach list bestsellerów, a nazwiska współczesnych morderców są wpisywane w paski przeglądarek internetowych równie często, co gwiazd kina i muzyki (Schmidt, 2005, s. 175). Ta specyficzna mieszanina celebryctwa, zbrodni i mediów nie wydaje się tak zadziwiająca, jeśli weźmie się pod uwage fascynację, jaką od XIX w. nieprzerwanie wzbudza Kuba Rozpruwacz, prawdziwa ikona kultury popularnej. David Schmidt (2005) diagnozuje wzrastająca popularność narracji na temat zbrodni, która w swoim centrum stawia mordercę raczej niż detektywa, jako sposób „uczłowieczenia” samej zbrodni, nadania ludzkiej twarzy doniesieniom o najczęściej anonimowanych aktach przemocy. Schmidt skupia się raczej na fikcyjnych postaciach. Studia poświęcone temu, co Ryan Broll nazwał „mrocznymi fandomami” (2018), czyli społecznościom fanowskim utworzonym wokół rzeczywistych (historycznych i współczesnych) morderców, nadal raczkują, a najczęściej analizowanym przypadkiem w tym nurcie badań są właśnie Columbiners (Paton, 2012; Paton \& Figeac, 2015; Raitanen, Sandberg \& Oksanen, 2017; Raitanen \& Oksnanen, 2018). Jak zauważa Broll, dotychczasowe ujęcia mają tendencję do analizowania „mrocznych fandomów” jako kulturowych anomalii, w oderwaniu od szerszego kontekstu społecznego (Broll, 2018, s. 793). Tymczasem już samo zastosowanie w analizie tych zjawisk kluczowych pojęć medioznawstwa i fan studies, takich jak afekt, relacja paraspołeczna czy celebryctwo, pozwala wyjść poza wyjaśnienia z gruntu psychologii i spojrzeć na niepokojący fenomen kulturowy w szerszej perspektywie, która ujawnia konwencjonalny charakter fanowskich aktywności Columbiners i niejako łagodzi lęki związane z „mrocznymi fandomami”.

Analizę zacząc jednak należy od omówienia wydarzeń, które doprowadziły do masakry, oraz jej następstw społecznych i kulturowych, czyli tego wszystkiego, co składa się na treść fanowskich aktywności w społeczności Columbiners, dla której działania nastoletnich zabójców oraz ich literacka i filmowa „spuścizna” stanowią teksty fundacyjne. W ten sposób nakreślimy ramy zachodzącej w fandomie reinterpretacji owych tekstów.

Harris i Klebold zaprzyjaźnili się w siódmej klasie szkoły średniej. Według doniesień ich znajomych, dwójka nastolatków była obiektem szykan ze strony rówieśników. W styczniu 1998 r. zostali aresztowani za włamanie się do miniciężarówki i kradzież elektronicznego sprzętu, który się w niej znajdował. Zrobili jednak dobre wrażenie na funkcjonariuszach i otrzymali propozycję usunięcia wpisu w rejestrze kryminalnym w zamian za wzięcie udziału w programie rehabilitacyjnym, który obejmował pracę społeczną i leczenie psychiatryczne. Harris uczęszczał na terapię, na której przepisano mu fluwoksaminę - lek antydepresyjny z grupy SSRI. Nastolatkowie w ramach procesu rehabilitacji musieli napisać list z przeprosinami do właściciela auta. List Harrisa zdawał się wyrażać szczerą skruchę; wyłaniał się z niego obraz wrażliwego, empatycznego młodego człowieka. Za dobre sprawowanie ukończyli program poprawczy kilka miesięcy wcześniej. Jednak później w dzienniku Harrisa ukazał się wpis, który już nie był tak przepełniony żalem za dokonane czyny, jak list do ofiary kradzieży: 
Czy Ameryka nie miała być krainą ludzi wolnych? Jak to możliwe, że ja, człowiek wolny, nie moge pozbawić jakiegoś tępego skurwiela jego własności, jeśli zostawia je na przednim siedzeniu swojego gównianego vana, pośrodku niczego, w piątkową noc? Selekcja naturalna. Skurwiela powinno się zastrzelić (Harris, 1998).

W grudniu 1998 r. Harris i Klebold, prawdopodobnie na zaliczenie projektu szkolnego, stworzyli krótki film pt. Hitmen for Hire. Nastolatkowie wcielili się w płatnych morderców, a ich klientami byli prześladowani uczniowie, towarzyskie wyrzutki w szkole w Columbine. W filmie Eric i Dylan ubrani w długie, czarne płaszcze, z twarzami schowanymi za okularami przeciwsłonecznymi, wysuwali wulgarne groźby wobec swoich ofiar oraz odgrywali ich odstrzeliwanie na korytarzach Columbine. Nie zostało potwierdzone, czy Hitmen for Hire był odtworzony na zajęciach. Film wygląda jednak na „próbę generalną” masakry w Columbine High School, która wydarzyła się cztery miesiące po nagraniu. Oprócz 8-minutowego Hitmen for Hire światło dzienne ujrzał również 16-minutowy materiał z Rampart Range, w którym Eric i Dylan trenują technikę i celność strzelania niedługo przed zaplanowaną zbrodnią. Mordercy nagrali też kilka filmów znanych jako The Basement Tapes, w których mówią o planach działania, prezentują zgromadzoną broń palną oraz fantazjują o tym, kto wyreżyseruje ich historię: Quentin Tarantino czy Steven Spielberg. Nagrania te nie zostały jednak opublikowane przez policje w obawie przed tym, że mogą posłużyć jako instrukcja i inspiracja do ataku na kolejne instytucje szkolne. Zamiast tego udostępniono 11 ooo stron akt śledztwa oraz liczący 900 stron raport, który opisywał dokładnie proces sekcji zwłok wszystkich ofiar.

Masakra w Columbine High School wzbudziła olbrzymie zainteresowanie mediów i opinii społecznej. W 1999 r. 68\% Amerykanów przyznało, że śledziło na bieżąco informacje o zdarzeniu w środkach masowego przekazu (Pew Reaserch Center for the People and the Press, 1999). Media wzięły sobie za cel wyjaśnienie tej wielowątkowej katastrofy. Jednocześnie w dyskursie medialnym oferowano uproszczone odpowiedzi i analizy. Wytworzył się swoisty spektakl medialny, którego bohaterami stali się wyalienowani młodzi ludzie powiązani z subkulturą gotycką (Frymer, 2009, s. 1392). Doprowadziło to do napiętnowania (i tak już zmarginalizowanych) outsiderów, w których opinia publiczna widziała potencjalne zagrożenie. Rozpoczęła się również medialna bitwa z zespołem Marilyn Manson, a zwłaszcza z jego frontmanem. Muzykę i wizerunek grupy określono jako gloryfikującą przemoc i stwierdzono, że stanowiły one główną inspirację dla dokonanej strzelaniny, a sam Marilyn Manson miał być przedmiotem kultu sprawców masakry. Nawet po udowodnieniu, że Eric i Dylan nie byli fanami zespołu, media kontynuowały nagonkę na artystę. Odpowiedzialnością za masową zbrodnię obarczono także zespół Nine Inch Nails oraz film Matrix (1999). Jednak panika moralna o najszerszym zasięgu rozpętała się, gdy potwierdzono, że Harris i Klebold byli fanami gier typu First Person Shooter takich jak Doom i Quake. Masakra w Columbine High School stała się kluczowym 
momentem w dyskusji na temat przemocy w grach komputerowych. Pomimo tego, że wcześniej miały miejsce inne szkolne strzelaniny (Kadoka, Kentucky, Jonesboro i Arkansas), gdzie też zastanawiano się nad wpływem gier na działania sprawców, przypadek Columbine - ze względu na skalę przemocy i niejednoznaczność sytuacji - zwrócił uwage polityków i mediów, kształtując ich negatywne stanowisko w stosunku do gier komputerowych. Linda Sanders, żona nauczyciela zamordowanego podczas strzelaniny, wraz z jego pasierbicami, złożyła pozew przeciwko 25 firmom-gigantom z branży gier, takim jak Nintendo i Sony. Argumentowała w nim, że Harris i Klebold zabijali i ranili niewinnych ludzi właśnie pod wpływem brutalnych filmów i gier wideo. Wskazała na takie gry jak Mortal Kombat, Wolfenstein, Mech Warrior, Nightmare Creatures, Restident Evil, Final Fantasy, Redneck Rampage oraz oczywiście wspomniane już Doom i Quake. Oskarżono zarówno twórców, jak i dystrybutorów gier. Pozew później oddalono, argumentując, że oskarżeni nie mieli powodu przypuszczać, że Harris i Klebold będą chcieli wkroczyć z bronią na teren swojej szkoły. Sędzia zacytował orzeczenie wydane przez federalny sąd apelacyjny w Chicago podczas sporu dotyczącego ograniczenia nieletnim dostępu do brutalnych gier wideo: „Przemoc zawsze była i nadal pozostanie w centrum zainteresowania ludzkości, jest też powracającym, czasem wręcz obsesyjnie, motywem w kulturze zarówno wysokiej, jak i niskiej” (Abbot, 2002).

Demonizacja gier wideo przez media i polityków przyniosła jednak pewien pozytywny skutek. Przed masakrą w Columbine nie przeprowadzano na szeroką skalę badań psychologicznych, psychiatrycznych czy socjologicznych na temat recepcji przemocy w mediach. Żywa dyskusja o wpływie gier na wzbudzanie skłonności do przemocy i agresji zaowocowała nowym dyskursem naukowym. Dzięki temu dzisiaj mamy dostęp do szeroko zakrojonych badań na ten temat, które niemal jednogłośnie stwierdzają absolutny brak korelacji między graniem w gry, w których pojawia się przemoc a strzelaninami w szkołach (Ferguson, 2008, s. 27). 4 maja 1999 r. Komisja Senacka Stanów Zjednoczonych ds. Handlu, Nauki i Transportu zorganizowała przesłuchanie dotyczące marketingu i dystrybucji wśród nieletnich treści medialnych zawierających przemoc. Oprócz osób o konserwatywnym podejściu do kultury popularnej, takich jak były Sekretarz Edukacji William Bennett, arcybiskup Charles J. Chaput czy polityk z ramienia partii demokratycznej Joseph Lieberman, przesłuchano także Henry’ego Jenkinsa - uznanego amerykańskiego medioznawcę. Rok wcześniej Jenkins wydał monografie From Barbie to Mortal Kombat: Gender and Computer Games, dotyczącą związku między płcią, nowymi technologiami a grami komputerowymi. Jak sam twierdzi, od tego czasu często jest proszony o wypowiedzenie się na temat przemocy w grach (Jenkins, 2006, s. 189). Na potrzeby przesłuchania Jenkins przeprowadził rozmowy z młodymi ludźmi zamieszkującymi dom studencki MIT, którego jest opiekunem. Zapytał studentów o ich reakcje związane z masakrą w Columbine High School oraz przemyślenia na temat trwającej wtedy wrzawy medialnej. Podczas przesłuchania Jenkins zwrócił uwage na to, że aktywne szukanie winowajcy w kulturze popularnej i mediach 
jest skutkiem paniki moralnej, która jest napędzana strachem przed nowymi technologiami, konfliktem pokoleniowym oraz zwiększającą się widocznością i znaczeniem mediów przeznaczonych dla młodzieży. Zauważył, że żaden element kultury konsumowany przez Harrisa i Klebolda nie jest bezpośrednio powiązany ze skłonnościami do przemocy. Nonkonformistyczny styl ubierania się sprawców, zawierający elementy estetyki gotyckiej, brutalne gry komputerowe czy muzyka industrialna stanowią kulturowe symbole poczucia alienacji i wściekłości młodzieży, a nie ich przyczyny (Jenkins, 1999).

W 2005 r., w szóstą rocznicę masakry, Danny Ledonne wydał 16-bitową grę Super Columbine Massacre RPG!, opartą na strzelaninie z 1999 r. Gracz mógł wcielić się w Harrisa lub Klebolda, by odtworzyć dokonane przez nich morderstwa. Po dokonaniu samobójstwa przez postacie, graczowi ukazywał się montaż fotografii zwłok nastolatków, zrozpaczonych rówieśników oraz zdjęcia z dzieciństwa obu morderców. Druga połowa gry ma miejsce w piekle, w którym Klebold walczy z postaciami z Doom. Po zwycięskiej walce dołącza do niego Harris i w miejscu określanym jako Island of Lost Souls spotykają fikcyjne postaci, takie jak Pikachu, Bart Simpson lub Mario, a także postaci historyczne, np. Johna Lennona, Malcolma X czy Ronalda Reagana. Na koniec gry para wręcza Fryderykowi Nietzschemu kopię Ecce Homo, po czym walczy z Szatanem z animowanego serialu South Park. Po zwycięstwie postać Szatana składa im gratulacje z tytułu ich dokonań. Gra kończy się powrotem do Columbine, gdzie odbywa się konferencja prasowa dotycząca strzelaniny, na której poruszane są wątki fundamentalizmu religijnego, bezsensownego obarczania przez media winą Marilyna Mansona czy gier wideo, a także legalnego, zbyt łatwego dostępu do broni palnej. Gra spotkała się ze rozbieżnymi reakcjami. Rodziny zamordowanych oraz głównonurtowe media uznały, że gra trywializuje całe wydarzenie i wykazuje brak szacunku dla ofiar. Jednak według niektórych jest ona swoistym znakiem uznania dla samego medium, jakim są gry wideo, hołdem dla kulturowego wpływu tej formy komunikacji. W wywiadzie przeprowadzonym przez Jenkinsa Ledonne mówił o podwójnym standardzie narzuconym grom komputerowym. Określił je jako synergię istniejących tradycji medialnych, sztuk wizualnych, projektowania graficznego, muzyki, literatury oraz kina. W jego ujęciu wartością gier komputerowych, która odróżnia je od tradycyjnych środków przekazu, jest interaktywność, pozwalająca graczowi w mniejszym lub większym stopniu kontrolować świat przedstawiony, co z kolei zapewnia większą immersję, a więc zaangażowanie. Obecnie gry komputerowe są oceniane jak produkty, w takich kategoriach jak grafika, dźwięk czy grywalność. W takim systemie oceny Super Columbine Massacre RPG! uplasowało się na drugim miejscu na liście dziesięciu najgorszych gier wszechczasów według miesięcznika „PC World”. Jednak gra została doceniona przez recenzentów za śmiałe użycie swojej formy do krytyki współczesnego wydarzenia społecznego. W związku z tym Ledonne zastanawia się, czy każda gra może kwalifikować się do miana sztuki. Być może gry jako dzieła sztuki powinny wymagać od gracza zaangażo- 
wania emocjonalnego i intelektualnego, a nie tylko umiejętności strategicznego myślenia i taktyki (Jenkins, 2008).

Masakra w Columbine High School zainspirowała wielu naśladowców. Efekt Columbine zaczął być widoczny już osiem dni po tragedii, kiedy doszło do masakry w W.R. Myers High School w Kanadzie, gdzie Todd Cameron Smith otworzył ogień na korytarzu, po czym udał się do stołówki i zabił tam jedną osobę, a kolejną ranił. Według rodziny sprawcy, jego zachowanie zmieniło się po obejrzeniu reportażu o strzelaninie w Columbine. 21 marca 2005 r. 16-letni Jeffrey Weise najpierw zabił swojego dziadka (który był funkcjonariuszem policji) oraz jego partnerkę, a następnie udał się do szkoły w Red Lake, której uczniem był kilka miesięcy wcześniej, gdzie zabił siedem osób, a pięć zranił, na koniec popełniając samobójstwo. Według świadków Weise podczas strzelaniny zapytał jednego z uczniów czy wierzy w Boga - dokładnie to samo pytanie zadał Klebold jednej z osób ocalałych z masakry, Valeen Schnurr (Lennard, 2005). Z kolei sprawca strzelaniny w Virginia Tech nazwał siebie „męczennikiem, takim jak Eric i Dylan” (CNN, 2007), natomiast Adam Lanza, morderca, który zabił 27 osób (w tym 12 dzieci), po czym popełnił samobójstwo w szkole podstawowej Sandy Hook, przejawiał fascynację masakrą w Columbine oraz posiadał na swoim komputerze mnóstwo materiałów dotyczących tego wydarzenia, udzielał się też na forum fanowskim Columbiners (NBC News, 2013).

Efekt Columbine przejawia się również w kulturze popularnej. W $2003 \mathrm{r}$. powstał film pt. Elephant w reżyserii Gusa Van Santa, oparty na wydarzeniach związanych z masakrą w Columbine High School. Obraz ten został nagrodzony Złotą Palmą na 56. Międzynarodowym Festiwalu Filmowym w Cannes. Innym filmem opartym na wydarzeniach z Columbine jest Zero Day w reżyserii Bena Coccio (2003). Jednak najbardziej frapujące przejawy efektu Columbine można spotkać obecnie na platformie multiblogowej Tumblr. Przez lata, wraz z rozwojem mediów społecznościowych, ukształtował się tam bowiem kontrowersyjny fandom sprawców strzelaniny, migrując z forów internetowych na inne platformy (dzisiaj przede wszystkim Tumblr i DeviantArt).

Według Johna Fiske'a, fandom jest zjawiskiem kultury popularnej, w przypadku którego skupienie się odbiorców na wybranej postaci, gatunku lub fabule prowadzi do powstania społeczności opartej na podzielanej wspólnie fascynacji i afekcie (Fiske, 1992, s. 46). Afektywność fanowska (która nie zawsze oznacza uwielbienie, ale stanowi splot skomplikowanych uczuć i emocji, przede wszystkim fascynacji) nie ogranicza się do postaci fikcyjnych, ale obejmuje także celebrytów oraz inne figury publiczne. True Crime Community (TCC) to fandom, który skupia się na przestępcach (szczególnie seryjnych mordercach) i zajmuje się wyszukiwaniem informacji na temat zbrodni i niuansów z nimi związanych, gromadzeniem informacji o życiu i przeszłości morderców. Ma to służyć zrozumieniu ich motywacji oraz przyczyn i kontekstów zbrodni, a także teoretyzowaniu na temat nierozwiązanych zagadek kryminalnych. Podstawowymi materiałami fanowskich eksploracji są w tym przypadku informacje prasowe i re- 
portaże z gatunku true crime oraz opracowania kryminalistyczne. Biorąc pod uwage, że true crime stanowi jeden $\mathrm{z}$ najpopularniejszych gatunków podcastów ${ }^{2}$ (trzecie miejsce pod względem popularności w 2020 r. według badań przeprowadzonych przez Statista), a produkcje w rodzaju Mindhunter (2017-2019) i Alienist (2018-2020) stają się dochodowymi hitami, można wysnuć wniosek, że TCC stanowi jedną z największych grup konsumenckich we współczesnej kulturze popularnej. Tak duży fandom skupiony wokół gatunku, który posiada liczne i zróżnicowane realizacje, również musi pozostać heterogeniczny i niespójny, czego przykładem jest podgrupa wielbicieli nie tyle zbrodni i kryminologii, co samych zbrodniarzy i morderców.

Środowisko TCC zainteresowane kryminologią wyraźnie oddziela się od podgrupy fanów romantyzującej seryjnych i masowych morderców, tworzących tzw. Serial Killer Fandom, do którego m.in. należą Columbiners, czyli fani, a najczęściej fanki ${ }^{3}$ Harrisa i Klebolda (Smith, 2018-2019, s. 140). Członkowie fandomu TCC uważają, że ta podgrupa niszczy wizerunek całej społeczności i podkreślają, że pod żadnym pozorem nie popierają działań fanowskich podejmowanych przez Columbiners. Na blogach TCC poświęconych masakrze w Columbine High School w swoich biogramach autorzy często piszą „I Do Not Condone” (pol. nie popieram), aby pokreślić, że nie gloryfikują zabójców, a jedynie interesują się wydarzeniem w ujęciu kryminologicznym. Z kolei członkowie fandomu Columbiners za swoje hasło uznają „In Eric and Dylan I Live” (pol. żyję w Eriku i Dylanie), powtarzając tę frazę na blogach i stronach internetowych (Raitanen \& Oksanen, 2018, s. 3). Członkowie Serial Killer Fandom spotykają się więc z jednoznacznym moralnym potępieniem i odrzuceniem ze strony TCC nie ze względu na przedmiot zainteresowania (on bowiem jest wspólny - postać rzeczywistego mordercy), ale na sposób wyrażania swojego fanowskiego afektu. Znaczące jest to, że przedstawicielkom Columbiners powszechnie przypisuje się romantyczne umotywowanie zainteresowań prowadzące do gloryfikacji sprawców masakry i ich działań. Na potrzeby niniejszego artykuły taką opinię określam jako hipotezę hybristofilii. Analiza twórczości tego fandomu pozwala jednak stwierdzić, że dominują tu inne motywacje niż wskazana powyżej.

Fandom seryjnych i masowych morderców nie jest zjawiskiem nowym. Richard Ramirez i Ted Bundy jeszcze za swojego życia byli adorowani przez tłumy wielbicielek, które uczestniczyły w ich rozprawach oraz pisały do nich listy, gdy przebywali w więzieniu (Leyton, 1996, s. 13). Linda Polman w swoim repor-

2 Gatunek ten często powstaje oddolnie, a programy produkowane są jako wyraz fanowskiej fascynacji. Przykłądowo, Morbid: A True Crime Podcast, który od swojej premiery w 2018 r. wielokrotnie pojawił się na listach najlepszych produkcji z tego gatunku, prowadzony jest przez Alaina Urquhart i Ashleigh „Ash” Kelley. Urquhart jest pomocnikiem patologa, a Kelley fryzjerką.

3 W badaniu przeprowadzonym przez Jenni Raitanen, Sveinung Sandberg i Attę Oksanen w fandomie Columbiners na Tumblrze wzięło udział 22 respondentów, z czego 15 osób zidentyfikowało się jako kobiety, cztery jako mężczyźni, a trzy jako osoby niebinarne; wiek respondentów wynosił od 15 do 32 lat (Raitanen, Sandberg \& Oksanen, 2017, s. 4). 
tażu Laleczki skazańców. Życie z kara śmierci rozmawia z kobietami, które zdecydowały się nawiązać bliskie kontakty z więźniami czekającymi na egzekucję. Pochodzące z różnych krajów Europy bohaterki reportażu prowadzą zwykłe życie, mają stabilną pracę, brak doświadczeń związanych z łamaniem prawa, posiadają mężów i dzieci, decydują się jednak korespondować ze skazańcami ze Stanów Zjednoczonych, odsiadującymi wyroki za mrożące krew w żyłach morderstwa i gwałty, często czekającymi na wykonanie kary śmierci. Z czasem znajomość się rozwija - kobiety wysyłają więźniom pieniądze na lepsze jedzenie, podstawowe środki higieny, ubrania, witaminy, książki oraz na papier, długopisy i znaczki pocztowe, aby zapewnić stały kontakt. Jedna z rozmówczyń Polman porównuje tego typu relacje do popularnej w latach 9o. XX w. japońskiej elektronicznej zabawki Tamagotchi. Zasada jej działania polegała na opiece nad wirtualnym stworzeniem (karmienie, mycie, sprzątanie po nim, zabawa itd.), którego potrzeby należało zaspokajać w odpowiednim czasie, aby pozostało „zdrowe” i „zadowolone” (Polman, 2018, s. 44). W przypadku więźniów kobiety z każdym listem coraz bardziej angażują się w relację, która zabiera im znaczną część wolnego czasu i pieniędzy. W końcu decydują się spotkać ze swoimi korespondentami osobiście. Więźniowie często wyznają, że zostali niewinnie skazani i proszą kobiety o zorganizowanie komitetu obrony, który miałby zebrać pieniądze na opłacenie dobrego adwokata. Atrakcyjność tego typu relacji może wynikać z pewnej zależności więźniów od tych kobiet. Jedna z rozmówczyń Polman, która poślubiła skazanego na śmierć, wyznaje, że odpowiada jej ta relacja, ponieważ mężczyźni z celi śmierci za wszelką cenę starają się stale oczarowywać kobietę listami, by podtrzymać zainteresowanie.

Według Katherine Ramsland, amerykańskiej profesorki psychologii sądowej, skazańcy są „idealnymi partnerami”. Kobieta pozostająca w związku z takim mężczyzną może czuć wewnętrzny spokój, bo zawsze wie, gdzie znajduje się jej partner oraz co prawdopodobnie robi. Wie, że o niej myśli i ją kocha, ale jednocześnie nie musi się zmagać z mniej atrakcyjną, rutynową codziennością i innymi problemami, które dotykają tradycyjne związki. Relacja ze skazańcem posiada także termin ważności. Administrator holenderskiej strony umożliwiającej korespondencję $\mathrm{z}$ więźniami wyznaje, że skazani na dożywocie nie cieszą się popularnością wśród kobiet pragnących nawiązać tego typu stosunki, ponieważ są „długoterminowym zobowiązaniem” (Ramsland, 2012, s. 57). Częstą diagnozą stawianą kobietom zafascynowanym takimi przestępcami jest hybristofilia, nazywana także „syndromem Bonnie i Clyde'a”. Jest to forma parafilii, w której obiektem pożądania seksualnego są osoby o przestępczej przeszłości, szczególnie zawierającej tak brutalne akty, jak morderstwo czy gwałt. Według Ramsland fascynacja taka może wynikać z różnych przyczyn, m.in. chęci przyczynienia się do resocjalizacji i zmiany przestępcy w dobrego człowieka. $Z$ drugiej strony kobiety mogą postrzegać więźnia jako małego chłopca potrzebującego opieki lub traktować go jako okazję do romantycznego związku, którego nie można skonsumować, co w ich przypadku jest zaletą, ponieważ boją się zaangażowania i intymności (Ramsland, 2012). 
Z kolei zwolennicy wyjaśnień ewolucyjnych porównują takie kobiety do samic szympansów, które wybierają większych i bardziej agresywnych partnerów (Polman, 2018, s. 62). W tym ujęciu przestępcy instynktownie są postrzegani jako „bardziej męscy” i silniejsi, a te cechy miałyby zapewniać kobietom ochronę oraz poczęcie silnego potomstwa. Kobiety korespondujące ze skazańcami w mediach przedstawiane są często jako więzienne groupies. „Laleczki skazańców” uważają, że są niesprawiedliwie postrzegane jako osoby patologiczne, co stanowi analogię do Columbiners, której przedstawicielki twierdzą, że są niesłusznie demonizowane przez środowisko True Crime Community. Bohaterki reportażu Polman wyraźnie dystansują się również wobec kobiet, które dają się wykorzystywać i manipulować przez skazańców, będąc dla nich jedynie źródłem finansowania. Rozmówczynie dziennikarki podkreślają własną sprawczość (agency), decyzyjność i samoświadomość, także co do tego, że ich motywacje i działania są nie tylko społecznie niezrozumiałe, ale wręcz demonizowane. Tego rodzaju fascynacja dorosłych kobiet skazańcami nie zawsze więc wpisuje się w hipotezę hybristofilii. Bogactwo motywacji ujawnione w reportażu Polman nie ogranicza się bowiem jedynie do seksualnej i/lub romantycznej fascynacji, obejmując zaspokajanie wielu innych potrzeby, np. kontaktu, kontroli, budowania poczucia własnej wartości i wyjątkowości itd. Jednak hipoteza hybristofilii jest najbardziej nośna społecznie, stając się najczęściej przypisywaną motywacją zarówno tytułowym „laleczkom skazańców”, jak i przedstawicielkom Columbiners oraz innych podobnie „mrocznych fandomów”.

Fankami w grupie Columbiners są zazwyczaj osoby między 14 a 20 rokiem życia ${ }^{4}$. Ich działalność fanowska nie różni się znacznie od działalności innych fandomów na Tumblrze: wstawiają i reblogują wzajemnie swoje zdjęcia, GIF -y i GIF-sety, fanarty oraz posty tekstowe zawierające charakterystyczne dla ich fandomu żarty i nawiązania. Na ich awatarach widnieją wizerunki Erica lub Dylana. Nicki fanek nawiązują do sprawców, np. często zawierają sformułowania „Reb” (skrót od Rebel, pseudonim internetowy Harrisa) lub „VoDKa” (pseudonim internetowy Klebolda). Używają hashtagu \#serialkillerfandom, aby znaleźć osoby o podobnych zainteresowaniach i stworzyć społeczność. Jak zauważa Grace Smith, zawartość tumblerowych blogów Columbiners jest bardzo zróżnicowana: od czysto informacyjnych postów tekstowych o kryminologicznym charakterze (detale na temat życia i zbrodni nastoletnich morderców), do memów, fanartów i manipów przedstawiających Harrisa i Klebolda (Smith, 2018-2019, s. 140). Jak wszystkie inne fandomy Columbiners wyrażają swoje afektywne przywiązanie poprzez twórczość, co nadaje tej społeczności całkiem konwencjonalny charakter, a seryjni mordercy traktowani są jak standardowe postaci popkulturowych złoczyńców. Przykładowo, użytkowniczka o nicku ramierezmariee666 ogłasza, że przyjmuje prompty na fanfiction o seryjnych mordercach, obiecując przy tym: „Nie będę was osądzać”. Niektóre fanki zawężają pod względem tematycznym swoje pole zainteresowań, np. użytkowniczka

4 Dane na podstawie informacji z blogów. 
o nicku richeramirezfanfiction pisze wyłącznie fanfiction na temat Nocnego Prześladowcy (Richarda Ramireza), inna z kolei (psycopathicneighbor) tworzy fanarty przedstawiające zbrodnie dokonane przez słynnych seryjnych morderców (Smith, 2018-2019, s. 142).

Analizując tego rodzaju praktyki, trzeba wziąć pod uwagę to, z jakim trudem przychodzi odseparowanie tożsamości osoby fizycznej od tożsamości kreowanej w sferze cyfrowej (należałoby nawet zastanawiać się nad zasadnością wprowadzenia tego typu podziału) oraz uwzględnić nie tylko psychologiczne teorie ciągłości doświadczenia Ja, ale także znakowy charakter rzeczywistości postmodernistycznej zawarty w figurze symulakrum. Uczestnictwo w „mrocznym fandomie" może wzbudzać moralny niepokój postronnych obserwatorów, jeśli nie weźmie się pod uwage ważnych kontekstów społecznych, takich jak konwencjonalność aktywności fanowskich oraz swoista fikcjonalizacja zabójców. Innymi słowy, nie ma strukturalnej różnicy pomiędzy byciem fanem fikcyjnego złoczyńcy a fanem seryjnego mordercy. Ciekawie przedstawia to członek fandomu Columbiners, który wyznaje:

Z Erikiem i Dylanem łatwo się identyfikować. Dwa białe dzieciaki, które słuchały pełnej gniewu muzyki z innego kraju. Przed światem udawali tych fajnych złoczyńców. Założę się, że w prawdziwym życiu byli kujonami, nie do końca tak fajnymi, za jakich chcieli uchodzić, a wiele osób, zwłaszcza dzieciaków teraz, chciałoby być nimi lub się z nimi przyjaźnić. Słuchają tej samej muzyki, grają w te same gry. Nie byli brzydcy i kiedy ubierali te swoje „przebrania”, stawali się jakby komiksowymi antybohaterami (Raitanen, Sandberg \& Okasanen, 2017, s. 6).

Powyższa wypowiedź nie tylko wskazuje na celową stylizację Harrisa i Klebolda na popkulturowe ikony, ale też na mechanizm odbioru, który stylizację tę w pełni akceptuje. Zanika różnica pomiędzy byciem fanem Panishera, a przynależnością do fandomu Columbiners. A jednak w tym drugim przypadku kontekst społeczny daleki jest od obojętnegos. Aby poradzić sobie z tym dysonansem poznawczym (czy też afektywnym), Columbiners wypracowali szereg strategii reinterpretacyjnych (często polegających na stosowaniu wielu warstw autoironii), które stanowią sedno twórczości w tym fandomie. Wbrew powszechnej opinii (chociażby w społeczności TCC) fanowska interpretacja Columbiners nie ma na celu gloryfikacji aktów przemocy i postaci seryjnych zabójców, ale opiera się na zrozumieniu motywacji i utożsamieniu się z przeżyciami i doświadczeniami sprawców strzelaniny, szczególnie tymi poprzedzającymi samą zbrodnię.

5 O zacierającej się różnicy pomiędzy fikcją a rzeczywistością ze względu na znakowy charakter tej drugiej może też świadczyć nowa tendencja w fandomie globalnym, określana jako purity culture, gdzie fani fikcyjnych złoczyńców spotykają się z takim samym moralnym potępieniem, co członkowie Serial Killers Fandom, a „puryści” traktują samo zainteresowanie zbrodnią i ciemną stroną ludzkiej natury jako wyraz moralnej degeneracji. 
Masakra w Columbine High School przedstawiana jest często w fandomie Columbiners jako zemsta Klebolda i Harrisa za prześladowania, które ich spotykały (Cullen, 2009, s. 170). Prezentowanie sprawców jako wyalienowanych, pogrążonych $\mathrm{w}$ depresji jednostek, spotykających się $\mathrm{z}$ niezrozumieniem ze strony reszty świata, pozwala na reinterpretację postaci Erica i Dylana jako prawdziwych ofiar, do czego służy np. wykorzystywanie ich zdjęć z albumów szkolnych i innych dostępnych materiałów wizualnych poprzedzających zbrodnię lub tworzenie fanartów w formie rysunków i kolaży. Na blogach poświęconych masakrze w Columbine posty związane z Harrisem i Kleboldem przeplataja się z wpisami dotyczącymi niskiej samooceny fanek, depresji i frustracji z tym związanej. W tym ujęciu fanki mają możliwość poczucia więzi ze sprawcami i utożsamienia się $\mathrm{z}$ nimi.

Badacze tego zjawiska zauważają, że w przypadku szkolnych strzelanin dominująca narracją na temat motywacji sprawców jest znęcanie się nad nimi, nawet jeśli nie ma dowodów, że rzeczywiście zachodziło albo jeśli stanowiło tylko jeden z wielu czynników prowadzących do wybuchu przemocy (Raitanen, Sandberg \& Okasanen 2017, s. 2). Dominacja określonej narracji, podtrzymywana aktywnie przez kulture popularną, umniejsza znaczenie innych czynników, głęboko osadzonych w kulturze (homofobii, toksycznej męskości, łatwego dostępu do broni palnej) i umożliwia rezygnację z refleksji na temat negatywnych elementów kulturowego środowiska, w którym dorastają nastolatki. Doskonale ilustruje to przypadek paniki moralnej wokół masakry w Columbine, w wyniku której rozpaczliwie szukano bezpośredniej przyczyny tragedii wśród nowych elementów kulturowych (nowych form medialnych, subkultur młodzieżowych, gatunków muzycznych i filmowych itp.). Dominacja narracji o znęcaniu się nad sprawcami szkolnych strzelanin nie tylko pozwala uniknąc autorefleksji i wdrażania systemowych rozwiązań, ale też stwarza pole do współodczuwania i identyfikacji z mordercami. Takiemu ujęciu odpowiadają więc narracje osobiste, w których własne doświadczenie wykluczenia i bycia ofiarą prześladowań, przekłada się na zrozumienie dla sprawców masakry (Raitanen, Sandberg \& Okasanen 2017, s. 8). Kluczową emocją jest tu nie tylko współczucie, ale też gniew. Nils Böckler i Thorsten Seeger stwierdzili, że osoby dokonujące takich zbrodni funkcjonują w swoich fandomach jako „rzecznicy większej grupy” i w pewnym sensie „stają się przodownikami rewolucji wydziedziczonych” (2013, s. 334). Także Natalie E. Paton zauważa, że „mroczne fandomy” w rodzaju Columbiners stają się subkulturą, którą pozwala nastolatkom „zakwestionować zastane struktury społeczne" (2012, s. 206). Spojrzenie na Columbiners jako wyraz frustracji, alienacji i gniewu pozwala także zrozumieć fenomen popularności sprawców masakry wśród nastolatek i młodych kobiet w sposób, który podważa hipotezę hybristofilii.

Kobietom nakłada się kulturowe ograniczenia, jeżeli chodzi o ekspresję złości, gniewu i frustracji. Dla fanek Harrisa i Klebolda strzelanina w Columbine może być punktem odniesienia, kanałem przez który mogą wyrażać swoją wewnętrzną frustrację i wściekłość. Normy społeczne i kulturowe pozbawiają kobiety przy- 
zwolenia na ekspresję gniewu w sposób, który dopuszcza się w przypadku mężczyzn, czyli bezpośrednio, $\mathrm{w}$ formie przemocy fizycznej. Te kobiety, które zdecydują się wyrażać złość w równym stopniu, co mężczyźni, narażają się na ostracyzm. Podczas jednego z badań kobiety, które wyrażały złość i frustrację w trakcie rozmowy kwalifikacyjnej lub rozmowy w sprawie podwyżki, postrzegane były jako mniej lubiane, mniej kompetentne, mniej zasługujące na władze i niezależność oraz otrzymywały niższe pensje niż podobnie rozzłoszczeni mężczyźni (Brescoll \& Uhlmann, 2008, s. 273). W patriarchalnej kulturze kobiety są postrzegane jako podrzędne wobec mężczyzn, a ekspresja gniewu jest odbierana jako sygnał władzy i dominacji, a więc kulturowo przypisana tym ostatnim (Domagalski \& Steelman, 2007, s. 301). Badacze wskazują również na to, że po wyrażeniu złości kobiety mają skłonność do ruminacji, ponieważ obawiają się o to, jak mogą być postrzegane i jakie czekają ich konsekwencje. Oprócz konsekwencji społecznych, ponoszą one bowiem także wysokie koszty intrapersonalne (Kring, 200o, s. 220).

Hybristofilia jako wyjaśnienie fascynacji kobiet seryjnymi i masowymi mordercami być może trafnie diagnozuje pewną grupę fanek. Należy jednak wziąć pod uwage, że tego typu parafilie są stosunkowo rzadkie w społeczeństwie i nie można w ten sposób wytłumaczyć całego spektrum zachowań i motywacji fanek. Raitanen i Okasanen próbowały sklasyfikować członków Serial Killer Fandom i zaproponowały podział na następujące grupy: 1) badacze (researchers), którzy są motywowani pragnieniem zrozumienia, czemu doszło do strzelaniny, jaki miała przebieg itd.; 2) fanki (fangirls), które napędza romantyczna i/lub seksualna fascynacja sprawcami zbrodni; 3) Columbiners, których interesuje wyłącznie przypadek masakry w Columbine; 4) naśladowców (copycats), czyli patologiczne jednostki, które planują lub fantazjują o przeprowadzeniu analogicznego zamachu (Raitanen \& Okasanen, 2018, s. 7-10). W powszechnej opinii i w środowisku True Crime Community cała społeczność Columbiners składa się właśnie $\mathrm{z}$ fanek i potencjalnych naśladowców. Jednak wywiady przeprowadzone przez badaczki sugerują coś wręcz przeciwnego. Raitanen i Okasanen zauważają, że wyszczególnione przez nie kategorie tożsamościowe nie są stałe, a jedna osoba może łączyć kilka postaw fanowskich i motywacji lub przechodzić płynnie od jednej do drugiej. Co ciekawe, wśród 22 respondentów nie znalazła się ani jedna osoba autoidentyfikująca się wprost jako fanka w takim ujęciu. Respondentka $\mathrm{z}$ wywiadu $\mathrm{nr} 4$ określiła się jako fanka w związku z twórczością podejmowaną na platformie Tumblr, gdzie publikowała rysunki Klebolda, nie nazwała jednak swoich uczuć wobec mordercy mianem „romantycznych” (s. 8). Respondentka z wywiadu nr 6 daje za to wyraz frustracji w związku z obecnością fanek w społeczności Columbiners, określając je z lekceważeniem jako „napalone nastolatki, które lecą tylko na przystojnych morderców” (s. 9). Tego typu sentyment przejawia się w wielu wypowiedziach, co w zasadzie wskazuje na mityczny charakter hipotezy hybristofilii. Motywacja romantyczna i/lub seksualna nie występują bowiem wśród badanych członków fandomu Columbiners, a ich twórczość jest błędnie interpretowana zgodnie $\mathrm{z}$ tą hipotezą; identyfi- 
kacja jest tu mylona z gloryfikacją i romantyzacją. Działania członkiń „mrocznych fandomów" powinny więc być wyjaśniane nie przez rzekome, odgórnie przypisywane fonkom motywacje, ale przez ich sposób partycypacji w fandomie, gdzie prymarną formą aktywności jest twórczość.

Również kategoria naśladowców pozostaje niemal mityczna, wpisuje się w nią wprost bowiem zaledwie kilka osób (przede wszystkim sprawca strzelaniny w Sandy Hook). Tej kategorii używa się jednak do patologizowania wizerunku całej społeczności, która jest świadoma tego stanu rzeczy. W wywiadach przeprowadzonych przez Raitanen i Okasanen przewijają się negatywne refleksje na temat potencjalnych naśladowców strzelaniny, którzy rzekomo funkcjonują w fandomie (s. 10-11), jednak okazuje się, że tego typu jednostki są niemożliwe do bezpośredniego zidentyfikowania.

I chociaż opisany wizerunek Columbiners to kwitnące wśród nastolatków cyfrowe siedlisko paraflii i psychopatii, analiza postaw i twórczości fanowskiej ujawnia o wiele bardziej zatrważający obraz. W istocie bowiem fascynacja zbrodnią i afektywne przywiązanie do sprawców strzelaniny wyrażają nie tylko głębokie przeobrażenia współczesnej kultury medialnej, ale też stanowią wyraz nastoletniej samotności, alienacji, depresji i frustracji, które nie znajdują żadnego innego pozytywnego ujścia.

Przestępcy tacy jak Richard Ramirez czy Ted Bundy są „typowymi” przykładami obiektów hybristofilskiego pożądania seksualnego. Obaj mordercy byli uważani za charyzmatycznych, pewnych siebie oraz przystojnych. Podczas rozpraw nie okazywali skruchy i pokory. W odróżnieniu od nich Harris i Klebold są przedstawiani w mediach i w fandomie jako ofiary systemu, presji koleżeńskiej i oczekiwań środowiska, do których nie mogli się dostosować. W pamiętnikach pisali o tym, że są nierozumiani i odrzucani. Dlatego nastolatki skłonne do zachowań depresyjnych będą się z nimi raczej utożsamiać niż ich seksualizować. Harris i Klebold reprezentują stłumioną ekspresje gniewu swoich fanek.

Przypadkiem potwierdzającym taką diagnozę może być historia SolPais, aktywnej członkini Columbiners na Tumblrze, która kilka dni przed 2o. rocznicą masakry w Columbine High School przyleciała z Miami do Colorado. W sklepie z bronią w Littleton, niedaleko szkoły Columbine, kupiła strzelbę i amunicję. Jej ciało zostało znalezione dwa dni później - zmarła z powodu samobójczej rany postrzałowej. SolPais prowadziła internetowy dziennik, w którym wyrażała poczucie niezrozumienia, pragnienia samobójcze oraz opisywała plany zdobycia broni. Dziennik zawierał także rysunki przedstawiające Klebolda.

Historia ta może posłużyć jako ilustracja różnicy pomiędzy fankami Klebolda i Harrisa a „laleczkami skazańców” czy fankami Mansona, Bundy’ego lub Ramireza. Szczególnie Klebold jest idealnym destylatem wyalienowania i izolacji, jakich doświadczają bardziej odmienni i aspołeczni uczniowie oraz dorośli w grupach rówieśniczych. W fandomie popularna jest narracja ukazująca Klebolda jako „pierwszą ofiare” Harrisa. W tym ujęciu bardziej zdeterminowany, socjopatyczny nastolatek zdominował kolege i skłonił go do popełnienia zbrodni. Klebold jest postrzegany jako wrażliwy i depresyjny, podczas gdy Harris jest 
motywowany wściekłością i nienawiścią. Klebold przedstawiany jest jako nieśmiały, niepewny siebie, pogrążony w depresji i podążający za bardziej charyzmatycznym Harrisem.

Andrew Rico (2015) stwierdza, że obiekt fascynacji Columbiners jest swego rodzaju zakazanym owocem. Seryjni i masowi zabójcy zawsze przyciągają uwagę mediów, co z kolei można odczytać jako celebrowanie morderców, skoro poświęcenia im się tyle samo uwagi, co gwiazdom popkultury. Media przekazują informacje w określonym kontekście, ale nie kontrolują ich recepcji. Dlatego zabójcy potępiani na gruncie kultury głównonurtowej mogą zyskać całkowicie inny wizerunek w niszowym fandomie. Harris i Klebold pozostawili bardzo dużą ilość materiałów (pamiętniki, nagrania wideo, zdjęcia, strony internetowe), dzięki czemu można skutecznie tworzyć i przekształcać wizerunki tych przestępców. Fandom Columbiners powstał w znacznej mierze właśnie dzięki tym materiałom. Pozwoliły one na zaspokojenie potrzeby voyeuryzmu medialnego (rozumianego jako podglądactwo, odkrywanie tajemnic ludzi pojawiających się w mediach), pozostawiając jednak pełną niedopowiedzeń przestrzeń podatną na tworzenie mitów i domniemania na temat motywacji zabójców, co pobudza i podtrzymuje fascynację i zaangażowanie. Już sama obecność sprawców masakry w dyskursie medialnym może zostać odczytana jako ich celebryfikacja. W efekcie pojawiania się wizerunków morderców na pierwszych stronach gazet i w portalach informacyjnych możliwe staje się nawiązanie $\mathrm{z}$ mini relacji paraspołecznej. Wraz z ciekawością i pragnieniem zrozumienia tragicznego wydarzenia prowadzi to do reinterpretacji wydarzeń poprzedzających masakrę w Columbine w oparciu o doświadczenia jednostek oraz ich osobistych narracji. Wbrew pozorom Columbiners nie różnią się więc od innych fandomów (zarówno ze środowiska True Crime Community, jak i pozostałych), a moralne potępienie, z jakim się spotykają, wynika z braku zrozumienia mechanizmów afektywnego przywiązania oraz zasad interpretacji i reinterpretacji tekstów obwiązujących w tym środowisku.

\section{BIBLIOGRAFIA}

Abbott, K., \& Able, C. (2002). Sanders' Video Game Lawsuit Dismissed. Retrieved from: http:// web.archive.org/web/20090307155939/http://www.rockymountainnews. com/drmn/local/article/o,1299,DRMN_15_1014458,oo.html

Binik, O. (2020). The Fascination with Violence in Contemporary Society. When Crime is Sublime. London: Palgrave Macmillan.

Böckler, N., \& Seeger, T. (2013). Revolution of the Dispossessed: School Shooters and Their Devotees on the Web. In N. Böckler, P. Sitzer, T. Seeger \& W. Heitmeyer (eds.), School Shootings: International Research, Case studies, and Concepts for Prevention (pp. 309-339). New York: Springer.

Boon, S. (2014). Why We Love Serial Killers. The Curious Appeal of the World's Most Savage Murders. New York: Skyhorse Publisher. 
Brescoll, V. L., \& Uhlmann, E. L. (2008). Can an angry woman get ahead? Status conferral, gender, and expression of emotion in the workplace. Psychological Science, 19(3), 268-275. doi: https:// doi.org/10.1111/j.1467-9280.2008.02079.x

Broll, R. (2018). Dark Fandoms: An Introduction and Case Study. Deviant Behavior, 41(6), 792-804. doi: https://doi.org/10.1080/o1639625.2019.1596453

CNN. (2007). Shooter: "You have blood on your hands". Retrieved from: http://edition. cnn. com/2007/US/ 04/18/vtech.nbc/

Cullen, D. (2009). Columbine. New York: Hachette Book Group Digital.

Domagalski, T. A., \& Steelman, L. A. (2007). The impact of gender and organizational status on workplace anger expression. Management Communication Quarterly, 2o(3), 297-315. doi: https://doi.org/10.1177/0893318906295681

Driessens, O. (2013). The Celebritization of Society and Culture: Understanding the Structural Dynamics of Celebrity Culture. International Journal of Culture Studies, 16(6), 641-657. doi: https://doi.org/10.1177/1367877912459140

Duclos, D. (1998). The Werewolf Complex: America's Fascination with Violence. Bloomsbury: London.

Duwe, G. (200o). Body-Count Journalism: The Presentation of Muss-Murder in the News Media. Homicide Studies, 4, 364-399. doi: https://doi.org/10.1177/1088767900004004004

Ferguson, C. J. (2008). The School Shooting/Violent Video Game Link: Causal Relationship or Moral Panic? Journal of Investigative Psychology and Offender Profiling, 5(1-2), 25-37. doi: https://doi.org/10.1002/jip.76

Frymer, B. (2009). The Media Spectacle of Columbine: Alienated Youth as an Object of Fear. American Behavioral Scientist, 52(10), 1387-1404. doi: https://doi.org/10.1177/ooo2764209332554

Harris, E. (1998). Journal. Retrieved from: http://acolumbinesite.com/eric/ writing/journal/journal.php

Jenkins, H. (1999). Congressional Testimony on Media Violence. Retrieved from: http://web.mit. edu/comm-forum/legacy/papers/jenkins_ct.html

Jenkins, H. (2006). Fans, Bloggers, Gamers: Exploring Participatory Culture. New York: New York University Press.

Jenkins, H. (2008). Playing Columbine: An Interview with Game Designer and Filmmaker Danny Ledonne (Part Two). Retrieved from: http://henryjenkins. org/blog/2008/10/playing_columbine_an_interview_1.html

Kring, A. M. (200o). Gender and anger. In A. H. Fischer (ed.), Gender and emotion: Social psychological perspectives (p. 211-231). Cambridge: Cambridge University Press.

Lennard, J. (2005). Ten Dead in US School Shooting. Retrieved from: https://www.theguardian. com/world $/ 2005 / \mathrm{mar} / \mathbf{2 2} /$ usgunviolence.usa

Leyton, E. (1996). Polowanie na ludzi. Studium masowych i seryjnych morderców naszych czasów (przeł. M. Otto). Warszawa: Al Fine.

NBC News. (2013). Police release full Newtown massacre report, with photos and video. Retrieved from: https://www.nbcnews.com/news/world/police-release-full-newtown-massacre-reportphotos-video-flna2d11812301

Paton, N. (2012). Media Participation of School Shooters and Their Fans: Navigating Between Self-Distinction and Imitation to Achieve Individuation. In G. W. Muschert \& J. Sumiala (eds.), School Shooting: Mediatizing Violence in Global Age (pp. 203-229). Bingley: Emerald GPL.

Paton, N., \& Figeac, J. (2015). Muddled Boundaries of Digital Shrines. Popular Communication, 13(4), 251-271. doi: https://doi.org/10.1080/15405702.2015.1019072

Pew Research Center for the People and the Press. (1999). Columbine Shooting Biggest News Draw of 1999. Retrieved from: http://people-press.org/report/48/columbine-shooting-biggest-news-draw-of-1999

Polman, L. (2018). Laleczki skazańców. Życie z kara śmierci (przeł. M. Diederen-Woźniak). Wołowiec: Wydawnictwo Czarne. 
Raitanen, J., \& Oksanen, A. (2018). Global Online Subcultures Surrounding School Shootings. American Behavioral Scientist, 62(2), 195-209. doi: https://doi.org/10.1177/ooo2764218755835

Raitanen, J., Sandberg, S., \& Okasanen, A. (2017). The Bullying-Scholl Shooting Nexus: Bridging Master Narratives of Mass Violence and Personal Narratives of Social Exclusion. Deviant Behavior, 4o(1), 1-14. doi: https://doi.org/10.1080/01639625.2017.1411044

Rico, A. R. (2015). Fans of Columbine Shooters Eric Harris and Dylan Klebold. Transformative Works and Cultures, 20. doi: https://doi.org/10.3983/twc.2015.0671

Ramsland, K. (2012). Women Who Love Serial Killers: Why Some Women Sacrafice So Much For Extreme Offenders. Retrieved from: https://www.psychologytoday.com/us/blog/shadow-boxing/201204/women-who-love-serial-killers

Schmidt, D. (2005). Natural Born Celebrities. Serial Killers in American Culture. Chicago: University of Chicago Press.

Smith, G. (2018-2019). Living Life on the Fringe: Examining How the Internet Has Enabled The Growth of Serial Killer Fringe Fandom. Comm-Entary: Media Rhetoric Interpersonal, 39, 139-152. 